\title{
Successful conservative treatment of spontaneous intrathoracic esophageal perforation using a temporary covered esophageal stent with a check valve: a case report
}

Ryu Matsumoto, Ken Sasaki*, Itaru Omoto, Masahiro Noda, Yasuto Uchikado, Takaaki Arigami, Yoshiaki Kita, Shinichiro Mori, Kosei Maemura and Shoji Natsugoe

\begin{abstract}
Background: Spontaneous esophageal perforation is a potentially life-threatening condition with high morbidity and mortality rates. While surgical treatment has been employed for esophageal perforation, we have adopted conservative treatment with an esophageal stent for patients in a poor physical condition because we consider controlling sepsis and improving the physical status are the highest priorities; additionally, the surgical trauma could be fatal for these patients.

Case presentation: A 60-year-old male complaining of left chest and back pain after vomiting was transferred to a local hospital. Computed tomography and chest $X$-ray examinations showed left tension pneumothorax, pneumomediastinum, and bilateral pleural effusion suspicious of spontaneous intrathoracic esophageal perforation. He was transferred to our hospital for further treatment. After arrival, he developed septic shock with acute respiratory failure. We considered that surgical treatment was too invasive and chose conservative treatment with an esophageal stent. Under general anesthesia, we first inserted a 20-Fr. trocar in the left posterior pleural space, and a large volume of the dark pleural effusion was discharged. We then performed endoscopy and found a pinhole perforation in the left posterolateral wall of the lower esophagus. We inserted both a silicon-covered esophageal stent with a check valve and a double elemental diet (W-ED) tube. We then inserted an 18-Fr. trocar into the left anterior wall. These procedures were performed less than $24 \mathrm{~h}$ after onset. As intensive medical care, the patient was administered broad-spectrum antibiotics and catecholamine. The two trocars and the W-ED tube were under continuous suction at $-5 \mathrm{cmH}_{2} \mathrm{O}$ and at $-20 \mathrm{cmH}_{2} \mathrm{O}$ every $30 \mathrm{~s}$. On the 6th day, we inserted an additional thoracic drainage tube into the left pleura under $\mathrm{CT}$ guidance. The patient was discharged from the ICU to the general ward on the 7th day. We removed the stent almost triweekly, and the esophageal perforation was completely healed on the 45th day. He was discharged home on the 70th day.
\end{abstract}

Conclusion: Conservative treatment with a temporary self-expanding covered stent with a check valve, sufficient drainage, and W-ED tube nutrition was useful and effective in this unstable case of spontaneous intrathoracic esophageal perforation.

Keywords: Spontaneous intrathoracic esophageal perforation, Conservative treatment, Covered esophageal stent with a check valve

\footnotetext{
*Correspondence: k-sasaki@m.kufm.kagoshima-u.ac.jp

Department of Digestive Surgery, Breast and Thyroid Surgery, Graduate

School of Medical and Dental Sciences, Kagoshima University, 8-35-1

Sakuragaoka, Kagoshima-shi, Kagoshima 890-8520, Japan
} 


\section{Background}

Spontaneous esophageal perforation is a potentially lifethreatening condition with high morbidity and mortality rates (ranging from 10 to $50 \%$ ) $[1,2]$ that can be complicated with mediastinitis, thoracic empyema, and severe sepsis. Because it can be fatal if not treated appropriately at an early stage $[3,4]$, prompt diagnosis and appropriate treatment plans are mandatory. While surgical treatment, such as primary repair or debridement, has been employed for esophageal perforation [5], conservative treatment is limited to patients with a disruption in the mediastinum or between the mediastinum and visceral lung pleura, drainage of the cavity back into the esophagus, minimal symptoms, and minimal signs of clinical sepsis [6]. We have adopted conservative treatment with a temporary self-expanding silicon-covered stent rather than surgical treatment for patients in a poor physical condition because we consider controlling sepsis and improving the physical status are the highest priorities; additionally, the surgical trauma could be fatal for these patients [7]. Here, we present a case of spontaneous intrathoracic esophageal perforation with septic shock successfully treated conservatively with a temporary selfexpanding silicon-covered stent with a check valve, sufficient drainage, and W-ED tube nutrition.

\section{Case presentation}

A 60-year-old male complaining of sudden left chest and back pain after the severe vomiting of alcohol was transferred to a local hospital. Computed tomography (CT) and chest X-ray examinations showed the findings of left tension pneumothorax, pneumomediastinum, and bilateral pleural effusion, suspicious of spontaneous intrathoracic esophageal perforation (Fig. 1). A 20-Fr. trocar was inserted into the left chest pleural cavity, and cloudy dark pleural effusion with gastric juice was discharged. He was transferred to our hospital by a helicopter for further treatment. On arrival, the patient was tachycardic (113 $\mathrm{bpm})$ and tachypneic (32 bpm) and showed signs of respiratory failure $\left(\mathrm{SpO}_{2}\right.$ of $96 \%$ with oxygen at $\left.8 \mathrm{~L}\right) . \mathrm{He}$ breathed with difficulty, and the breath sounds of the left chest were decreased. There was subcutaneous emphysema in the neck and chest. His face was pale, and his skin was cool and damp. The drain inserted in the previous hospital was removed accidentally during the transfer. His blood test results were as follows: total white blood cell count, 8600/L; platelet count, 229,000/L; C-reactive protein level, $25.68 \mathrm{mg} / \mathrm{dl}$; blood urea nitrogen level, $27.9 \mathrm{mg} /$ $\mathrm{dl}$; and serum creatinine level, $1.36 \mathrm{mg} / \mathrm{dl}$. Through the examinations, his general condition became worse and he began to show dramatic signs of septic shock. We diagnosed him with intrathoracic esophageal perforation and chose conservative treatment with esophageal stent and drainage of the chest and mediastinum rather than any aggressive surgical treatment because surgical trauma in such a critically ill patient could be fatal. We first transferred the patient to the operating room. The anesthetist administered an induction agent while applying cricoid

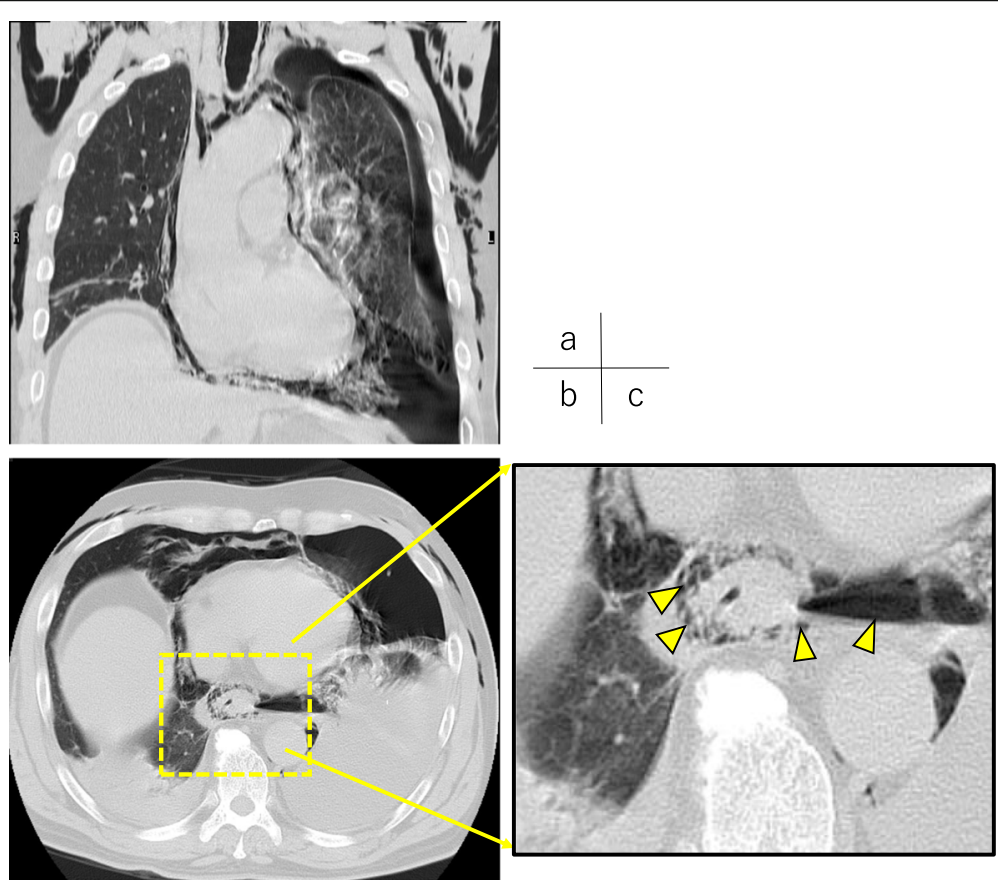

Fig. 1 Preoperative chest CT findings. Chest CT revealed left tension pneumothorax (a) and pneumomediastinum around the lower esophagus (arrowheads) (a-c). a Transverse section. b Lower esophagus. c Enlarged view of the lower esophagus 
pressure, and rapidly performed the intubation without positive pressure ventilation not to damage the perforation site of the esophagus (rapid sequence induction). Under general anesthesia, we inserted a 20Fr. trocar into the left posterior pleural space under fluoroscopic guidance; soon, approximately $1300 \mathrm{cc}$ of dark fluid with gastric juice was discharged, and then his vital signs became stable. We evaluated the location of the esophageal perforation by endoscopy and identified a pinhole in the left posterolateral wall of the lower esophagus (38 cm from an incisor) (Fig. 2a). We did not perform esophagography. We placed a silicon-covered stent with a check valve (HANROSENT $^{\oplus}$, M.I. Tech, Gyeonggi-do, Korea) at the esophagogastric junction (EGJ) to cover the area of the fistula (Fig. 2b-d). Next, we inserted a double elementary diet tube (W-ED ${ }^{\circ}$ tube, Covidien, Japan) into the duodenum and an $18 \mathrm{Fr}$. trocar into the left anterior wall. The operative time was $58 \mathrm{~min}$, and the bleeding volume was little. These procedures were performed less than $24 \mathrm{~h}$ after onset. As intensive medical care, the patient was administered broad-spectrum antibiotics and catecholamine. The bacterial culture of the blood did not represent any bacteria, but we firstly administered a broad-spectrum antibiotic and an antifungal drug, because our patient was susceptive of bacterial septic shock. Enteral nutrition with the W-ED tube was started on the next day. The two trocars and the $\mathrm{W}$-ED tube were under continuous suction at -5 $\mathrm{cmH}_{2} \mathrm{O} \mathrm{mmHg}$ and at $-20 \mathrm{cmH}_{2} \mathrm{O}$ every $30 \mathrm{~s}$. On the 6th day, we inserted an additional thoracic drainage tube into the left pleura under $\mathrm{CT}$ guidance due to fluid accumulation close to the perforation site, and the patient was discharged to the general ward on the 7 th day. We performed endoscopy to evaluate leakage using urografin and changed the esophageal stent almost triweekly. The fistula was healed on the 45th day (Fig. 3a) and the granulomatous tissue growth around the esophageal stent was found (Fig. 3b), and then the esophageal stent was finally removed on that day. On the 59th day, we removed the W-ED tube, and the patient began eating orally. The thoracic drainage tubes and trocars were removed, and he was discharged home on the 70th day. Endoscopy showed the complete healing of the fistula at 4 months (Fig. 3c).

\section{Discussion}

Spontaneous esophageal perforation, especially in patients with septic shock, is a lethal condition, and a prompt diagnosis and appropriate treatment are mandatory for a successful clinical course $[8,9]$. The esophagus lacks a protective serosal surface anatomically, and perforation of the esophagus can easily affect the surrounding tissue, leading to severe mediastinitis and emphysema of the pleural cavity [10]. The principles of managing esophageal perforation include controlling ongoing spillage from the esophagus, draining the pleural and/or mediastinal cavities, administering intravenous broad-spectrum antibiotics, performing gastric decompression, and providing enteral or parenteral nutritional support [9].

The treatment strategy for esophageal perforation is still controversial, especially regarding the control of spillage from the perforation site in patients with shock; in other words, whether surgical or nonsurgical management

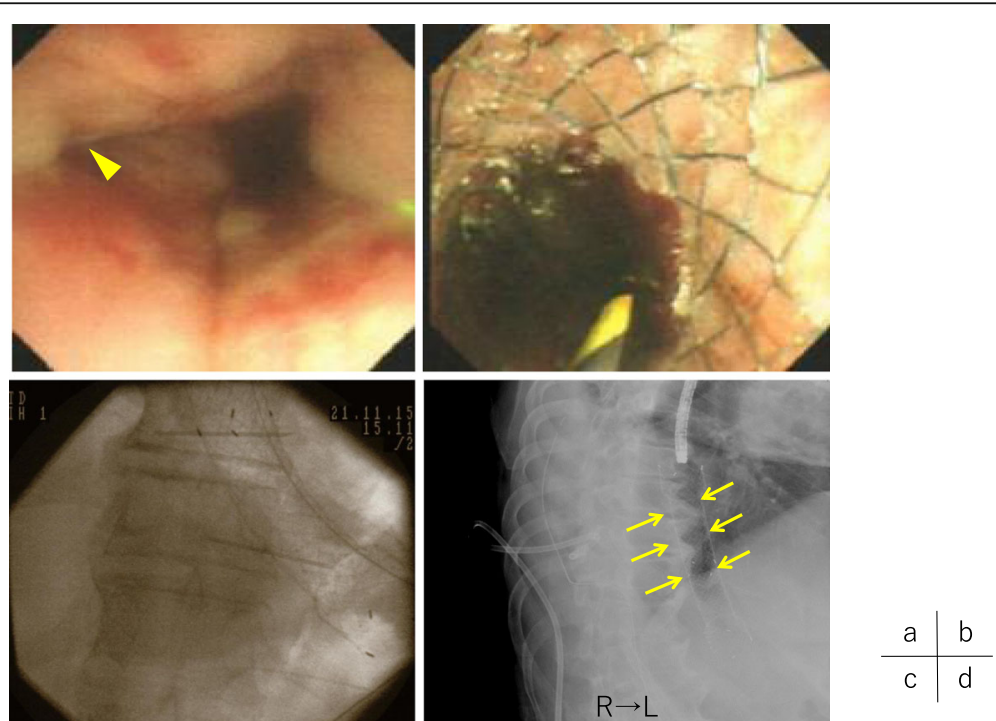

Fig. 2 Esophageal stent placement. a Endoscopy revealed a pinhole perforation in the left posterolateral wall of the lower esophagus (arrowhead). b-d Esophageal stent placement (arrows) (b endoscopy, c fluoroscopy, and $\mathbf{d}$ chest X-ray) 


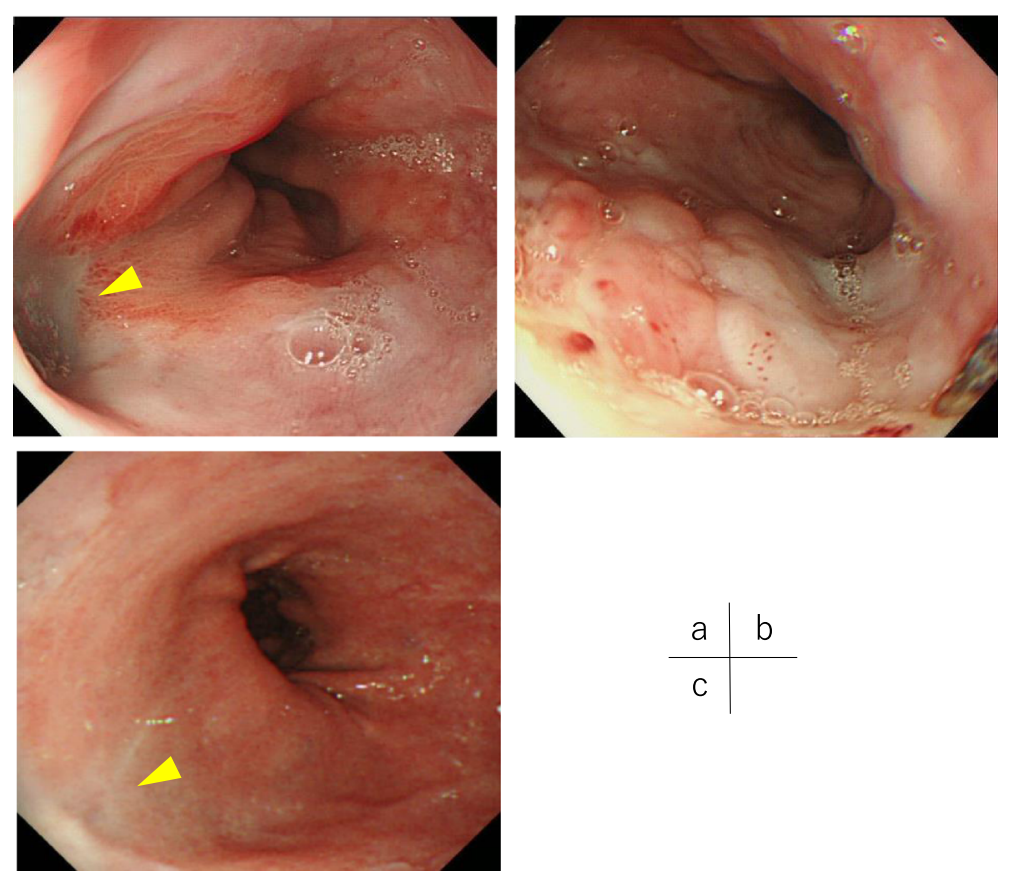

Fig. 3 Complete healing of the esophageal perforation. a Healing of the esophageal perforation on the 45th day (arrowhead). b There was granulomatous tissue growth around the esophageal stent. c Complete healing of the esophageal perforation at 4 months (arrowhead)

(conservative treatment) should be applied remains a matter of debate. Esophagectomy or primary repair is believed to be capable of eliminating the perforated esophagus as a source of sepsis and removing any underlying esophageal pathology $[11,12]$. However, many patients develop severe postoperative sepsis and cannot be cured [10, 13]. Recently, some authors reported laparoscopy or camera-assisted surgery as a less invasive procedure than thoracotomy for treating spontaneous esophageal perforation [14-16], but these techniques require a highly skilled operator and a longer operative time, and closure of the perforation site after $24 \mathrm{~h}$ is more likely to lead to dysraphia [17].

On the other hand, conservative treatment, which avoids surgical trauma and allows drainage and control of sepsis, has been used for esophageal perforation [18], especially in critically ill patients $[19,20]$. Vogel et al. reported an overall survival rate of $96 \%$ in 47 patients with esophageal perforation and emphasized that the aggressive treatment of sepsis and pleural fluid collection can prevent the need for major surgery [19]. In addition, the efficiency of self-expanding esophageal stents, such as the HANAROSTENT and SXELLA esophageal stents (ELLA-CS, Hradec Kralove, Czech Republic), in blocking the site of leakage has been reported, suggesting that they might help control sepsis and reduce mortality and morbidity $[9,21,22]$. Dasari et al. reported a technical success rate of stent placement of $91.4 \%$ and a healing rate of $81 \%$ [9]. To our knowledge, there have been only a few reports about the usefulness of "esophageal stent with a check valve" and "W-ED tube" for esophageal perforation. Oshiro et al. reported the successful management of staple line leakage at the esophagogastric junction after sleeve gastrectomy using the HANAROSTENT and its check valve at the distal end was effective to prevent gastroesophageal reflux [21]. Kimura et al. showed the usefulness of conservative treatment with fibrin glue injection and WED tube for esophageal perforation by a fish bone [23]. We believe using "esophageal stent with a check valve" and "WED tube" is beneficial to prevent the reflux of gastric juice to the fistula, especially to the fistula of the lower esophagus. Based on these reports, we think that the temporary placement of a self-expanding silicon-covered stent with a check valve is feasible for the treatment of critically ill patients with esophageal perforation. The use of esophageal stents in esophageal perforation has been reported to have some problems, such as the stent removal interval and stent migration [9]. An interval of esophageal stent replacement of approximately 3-8 weeks has been reported to avoid migration, fistula, and stenosis caused by granulomatous tissue growth [24], as well as the disruption of healed mucosa $[9,25]$. The rate of stent migration has been reported to be $20.8 \%$ [9] and is expected to be higher with the use of stents in non-stricture-related etiologies, such as iatrogenic or spontaneous esophageal perforation. There have been few reports on methods for preventing stent migration. We experienced a patient who required esophagectomy at 3 months after insertion because of granulomatous tissue 
growth around the esophageal stent. Based on this valuable experience, we usually perform endoscopy to evaluate the presence of granulomatous tissue around the stent, esophageal ulcers, and stent migration every 3-4 weeks. We consider that if the perforation occurred in the lower esophagus, placing the stent at the EGJ is the most important for preventing stent migration. We first measured the length of the perforation site from the EGJ and then placed a sufficiently long stent at the EGJ. In the present case, we removed the stent every 3 weeks, and we did not experience any trouble with the esophageal stents, which were effective for healing.

In this case, we diagnosed spontaneous intrathoracic esophageal perforation based on the findings of bilateral pleural effusion, tension pneumothorax, severe broad pneumomediastinum, and contaminated drainage from the left thoracic cavity. We first transferred the patient to the operating room and then performed thoracic drainage under general anesthesia. As the general condition of patients with spontaneous intrathoracic esophageal perforation is often poor [26], it is necessary to prepare for unexpected vital changes. We did not perform esophagography because of the stress on the perforation site exerted by the ionic watersoluble media and the limited sensitivity (80-90\%) [27]. Endoscopic visualization helps to identify the exact location of the perforation, extent of dehiscence, and viability of the esophageal mucosa [9]. Trained doctors perform endoscopy very carefully in a short time to avoid damaging the perforation site under $\mathrm{CO}_{2}$ insufflation to avoid worsening the pneumomediastinum. We used the HANAROSTENT stent to control the leakage from the fistula and the regurgitation of gastric juice to avoid outflow of the gastric juice through the fistula because this stent is removable, has a check valve, and is suitable for temporary applications. Furthermore, we placed the W-ED tube $(16 \mathrm{Fr}, 150 \mathrm{~cm}$ long, double lumen) into the jejunum for simultaneous jejunal nutrition and decompression of the stomach, which was also very effective for achieving early complete healing. When we suspected abscess formation based on the blood test and imaging findings, we immediately inserted an additional drainage tube under CT guidance.

In our institute, the first-line treatment plan for intrathoracic esophageal perforation, especially in patients with septic shock, has been conservative treatment to avoid surgical procedures, such as esophageal repair or esophagectomy, and often the placement of a temporary esophageal stent for spillage control. We treated 13 esophageal perforation cases from 2004 to 2019; among these, there were 4 cases, including this case, involving septic shock. We performed conservative treatment with esophageal stents, and we rescued all patients while avoiding surgical procedures [7]. Conservative treatment using esophageal stents with a check valve is effective in critically ill patients, but the further supporting evidence from additional cases is necessary for verification.

\section{Conclusions}

We successfully saved this patient with spontaneous intrathoracic esophageal perforation and septic shock by conservative treatment with a temporary self-expanding covered stent with a check valve, sufficient drainage, and W-ED tube nutrition.

\section{Abbreviations \\ CT: Computed tomography; EGJ: Esophagogastric junction; W-ED: Double elementary diet tube}

\section{Acknowledgements}

This manuscript was proofread by a professional editor who is a native speaker of English at Nature Research Editing Service (https://authorservices. springernature.com/language-editing/).

\section{Authors' contributions}

RM wrote the manuscript. KS helped to write the manuscript and supervised the study. All authors performed daily medical treatments in this case. SN comprehensively supervised this study. All the authors read and approved the final manuscript.

\section{Funding}

The authors declare that this work was not supported by any grants or funding support.

\section{Availability of data and materials}

Ethical approval was obtained from the Ethical Committee of Kagoshima University Hospital.

\section{Ethics approval and consent to participate}

This study was carried out in accordance with the principles of the Declaration of Helsinki.

\section{Consent for publication}

Written informed consent was obtained from the patient for publication of this case report and accompanying images.

\section{Competing interests}

The authors declare that they have no competing interests.

Received: 12 July 2019 Accepted: 27 September 2019

Published online: 24 October 2019

References

1. Costamagna G, Marchese M. Management of esophageal perforation after therapeutic endoscopy. Gastroenterol Hepatol. 2010;6:391-2.

2. Gupta NM, Kaman L. Personal management of 57 consecutive patients with esophageal perforation. Am J Surg. 2004;187:58-63.

3. Wolfson D, Barkin JS. Treatment of Boerhaave's syndrome. Curr Treat Options Gastroenterol. 2007:10:71-7.

4. Sulpice L, Dileon S, Rayar M, Badic B, Boudjema K, Bail JP, et al. Conservative surgical management of Boerhaave's syndrome: experience of two tertiary referral centers. Int J Surg. 2013;11:64-7.

5. Zumbro GL, Anstadt MP, Mawulawde K, Bhimji S, Paliotta MA, Pai G. Surgical management of esophageal perforation: role of esophageal conservation in delayed perforation. Am Surg. 2002;68:36-40.

6. Cameron JL, Kieffer RF, Hendrix TR, Mehigan DG, Baker RR. Selective nonoperative management of contained intrathoracic esophageal disruptions. Ann Thorac Surg. 1979;27:404-8

7. Okumura H, Uchikado Y, Kita Y, Omoto I, Hayashi N, Matsumoto M, et al. Clinical analysis of the diagnosis and treatment of esophageal perforation. Esophagus. 2016;13:146-50.

8. Lin $Y$, Jiang G, Liu L, Jiang JX, Chen L, Zhao Y, et al. Management of thoracic esophageal perforation. World J Surg. 2013;38:1093-9. 
9. Dasari BV, Neely D, Kennedy A, Spence G, Rice P, Mackle E, et al. The role of esophageal stents in the management of esophageal anastomotic leaks and benign esophageal perforations. Ann Surg. 2014;259:852-60.

10. Jones WG, Ginsberg RJ. Esophageal perforation: a continuing challenge. Ann Thorac Surg. 1992;53:534-43.

11. Sung SW, Park JJ, Kim YT, Kim JH. Surgery in thoracic esophageal perforation: primary repair is feasible. Dis Esophagus. 2002;15:204-9.

12. Freeman RK, Ascioti AJ. Esophageal stent placement for the treatment of perforation, fistula, or anastomotic leak. Semin Thorac Cardiovasc Surg. 2011;23:154-8.

13. Reeder LB, DeFilippi VJ, Ferguson MK. Current results of therapy for esophageal perforation. Am J Surg. 1995;169:615-7.

14. Mikami R, Nakamoto Y, Ikeda H, Kayata H, Murakami T, Yamamoto M. Primary closure of a spontaneous esophageal rupture under hand-assisted laparoscopy: a case report. Surg Case Rep. 2016:2:70.

15. Kimberley KL, Ganesh R, Anton CK. Laparoscopic repair of esophageal perforation due to Boerhaave syndrome. Surg Laparosc Endosc Percutan Tech. 2011;21:e203-5.

16. Vaidya S, Prabhudessai S, Jhawar N, Patankar R. Boerhaave's syndrome: thoracolaparoscopic approach. J Minim Access Surg. 2010;6:76-9.

17. Kaman L, Iqbal J, Kundil B, Kochhar R. Management of esophageal perforation in adults. Gastroenterol Res. 2010:3:235-44.

18. Martinez L, Rivas S, Hernandez F, Avila LF, Lassaletta L, Murcia J, et al. Aggressive conservative treatment of esophageal perforations in children. J Pediatr Surg. 2003;38:685-9.

19. Vogel SB, Rout WR, Martin TD, Abbitt PL. Esophageal perforation in adults: aggressive, conservative treatment lowers morbidity and mortality. Ann Surg. 2005;241:1016-21.

20. Arellano RS, Gervais DA, Mueller PR. Computed tomography-guided drainage of mediastinal abscesses: clinical experience with 23 patients. J Vasc Interv Radiol. 2011;22:673-7.

21. Oshiro T, Kasama K, Umezawa A, Kanehira E, Kurokawa Y. Successful management of refractory staple line leakage at the esophagogastric junction after a sleeve gastrectomy using the HANAROSTENT. Obes Surg. 2010;20:530-4.

22. Cayci HM, Erdoğdu UE, Dilektasli E, Turkoglu MA, Firat D, Cantay H. An unusual approach for the treatment of oesophageal perforation: laparoscopic-endoscopic cooperative surgery. J Minim Access Surg. 2017;13:69-72.

23. Kimura T, Takemoto T, Fujiwara Y, Yane K, Shiono H. Esophageal perforation caused by a fish bone treated with surgically indwelling drainage and fibrin glue injection for fistula formation. Ann Thorac Cardiovasc Surg. 2013;19(4):289-92.

24. Schweigert M, Beattie R, Solymosi N, Booth K, Dubecz A, Muir A, et al. Endoscopic stent insertion versus primary operative management for spontaneous rupture of the esophagus (Boerhaave syndrome): an international study comparing the outcome. Am Surg. 2013;79:634-40.

25. El H, Imperiale TF, Rex DK, Ballard D, Kesler KA, Birdas TJ, et al. Treatment of esophageal leaks, fistulae, and perforations with temporary stents: evaluation of efficacy, adverse events, and factors associated with successful outcomes. Gastrointest Endosc. 2014;79:589-98.

26. Hayashi N, Okumura H, Uchikado Y, Omoto I, Kita Y, Sasaki K, et al. Successful management of esophageal perforation using a removable selfexpanding covered metallic stent after endoscopic submucosal dissection for a patient with a history of gastrectomy. Esophagus. 2016;13:395-9.

27. Foley MJ, Ghahremani GG, Rogers LF. Reappraisal of contrast media used to detect upper gastrointestinal perforations: comparison of ionic watersoluble media with barium sulfate. Radiology. 1982;144:231-7.

\section{Publisher's Note}

Springer Nature remains neutral with regard to jurisdictional claims in published maps and institutional affiliations.

\section{Submit your manuscript to a SpringerOpen ${ }^{\circ}$ journal and benefit from:}

- Convenient online submission

- Rigorous peer review

- Open access: articles freely available online

- High visibility within the field

- Retaining the copyright to your article

Submit your next manuscript at $\boldsymbol{\nabla}$ springeropen.com 